\title{
Editorial
}

Digestion

Published online: November 25, 2005

\section{Do We Underestimate Capsule Endoscopy in the Upper Gastrointestinal Tract?}

\author{
Claus Schäfer Burkhard Göke \\ Medizinische Klinik II, University Hospital Grosshadern, Ludwig Maximilian University of Munich, \\ Munich, Germany
}

Since the first upper gastrointestinal (GI) endoscopy was performed in 1881 by Mikulicz-Radecki, marked advances have been achieved in our ability to view the GI tract. The introduction of flexible endoscopes facilitated intubation of deeper portions of the GI tract. However, for several decades endoscopy of the small bowel was rather limited to only a small portion of the closest upper bowel or tainted with a higher risk of complications when performing our so-called push endoscopies. Recently, a noninvasive method for examination of the small bowel has become available: capsule endoscopy (CE). The fiction of movie makers of simply swallowing a tablet-like instrument and thereby traveling through the GI tract seems realistic. In 2001 the Given Imaging System got FDA approval in the United States. Since its introduction, several studies have been performed which demonstrated a certain superiority of this method above push endoscopy in the detection of lesions leading to obscure GI bleeding [1,2]. The data presented to date clearly underline the usefulness of $\mathrm{CE}$ in the search for the sources of obscure GI bleeding. Pennazio et al. [3] evaluated the sensitivity and specificity of $\mathrm{CE}$ and the outcome after $\mathrm{CE}$ in 100 consecutive patients with obscure GI bleeding, and reported that the procedure helps in situations with ongoing obscure-overt bleeding or with obscure-occult bleed- ing. If done early in the course of the work-up, CE shortens the time to diagnosis and spares a number of alternative investigations with lower diagnostic yield. Taken together this seems appealing to doctors.

A somewhat puzzling fact is that, in the majority of studies done so far for established indications, in only a small proportion of patients does CE have a real impact on the clinical outcome - even at a higher diagnostic yield. This clearly argues in favor of focused diagnostic strategies when considering CE for a work-up. In a way this contrasts with attempts to look for additional indications for CE - sometimes probably encouraged by the manufacturer with the aim to simply sell more CE devices. From the data presented so far we have no reason to believe that $\mathrm{CE}$ is of any help in the differential diagnosis of diffuse abdominal pain. Data presented from studies in patients with Crohn's disease and polyposis syndromes seem interesting but have not really changed the diagnostic protocols. Here, modern enteroclysis techniques and double-balloon endoscopy are strong competitors.

In this issue of Digestion, Peter et al. present an analysis of the frequency of lesions picked up in the esophagus and the stomach by CE compared to previous esophagogastroscopy (EGD) findings. Although, the study has

\section{KARGER}

Fax +41613061234 E-Mailkarger@karger.ch www.karger.com
(C) 2005 S. Karger AG, Basel 0012-2823/05/0724-0239\$22.00/0

Accessible online at: www.karger.com/dig
Prof. Dr. Burkhard Göke

Medizinische Klinik II, Klinikum Grosshadern

Marchioninistrasse 15, DE-81377 Munich (Germany)

Tel. +49 897095 2390, Fax +49 8970958887

E-Mail burkhard.goeke@med.uni-muenchen.de 
some pitfalls (e.g. retrospective analysis, no clinical outcome reported, and the significance of the reported findings is unclear), the authors nevertheless point out that significant lesions were missed at EGD and only identified during CE. The capsule found more mucosal lesions in $9 \%$ of the patients in the stomach and in $8 \%$ in the esophagus. The authors call for a 're-look' EGD in the diagnostic algorithm after a positive capsule finding and an earlier negative EGD. Clearly, we cannot safely rely on previous endoscopy reports produced by others (and unfortunately also by ourselves) when ongoing bleeding from the upper GI tract still prompts questions. Anyway, the question is well taken care of in the literature on how upper GI endoscopy in the search of bleeding sources correlates with sensitivity and specificity.

Another arising idea is worth discussion. Is it really possible that such a capsule rapidly rushing through the esophagus and flipping around the stomach will be of help in the future in the diagnostic routine of the upper GI tract? Presently, the design of the capsule is made for the journey through the small intestine. The capsule rapidly passes through the esophagus with an unpredictable transmission, thus limiting the number of pictures, in particular, of the distal esophagus. Technical advances may help when a second camera is built into the device, thereby increasing the number of pictures taken in a second. The newly developed PillCam ESO Esophageal Capsule has already been evaluated in patients with suspected esophageal disease $[4,5]$. The aim is clear: to develop $\mathrm{CE}$ as a screening instrument in reflux patients. Up to now, a small pilot study has demonstrated that CE identified all suspected lesions found in the endoscopy before. In this study, the mean time for the passage through the esophagus was $189 \pm 280 \mathrm{~s}$. This seems unusually slow when compared to other reports and to our own experience. Another multicenter trial has compared the accuracy (specificity, sensitivity, positive predictive value, and negative predictive value) of CE with EGD in patients with gastroesophageal reflux disease. In this larger study 66 of 106 patients had positive endoscopic esophageal findings, CE identified esophageal abnormalities in 61 (sensitivity 92\%; specificity 95\%). In contrast, several studies have raised substantial doubts after studying the distal esophagus by $\mathrm{CE}$ trying to find an easy screening method for reflux lesions $[6,7]$. In any case, even if the CE could reliably prove that the specificity and sensitivity is nearly the same as for EGD, at least every patient with a pathologic result needs to get a EGD for biopsy or treatment. Therefore, endoscopy rather than $\mathrm{CE}$ will be offered to those with a clinical history of reflux. A combination of both will add significant costs to the work-up.

Will there be an indication for CE before EGD, for example $\mathrm{CE}$ as a general screening instrument to detect Barrett's esophagus in a population of people older than 45 years or to exclude cancer in those with dyspepsia? How will we then handle patients without pathology in the CE? Will we offer a consecutive endoscopy?

EGD still is the gold standard, safe in the hands of an experienced gastroenterologist and providing the opportunity for biopsies and treatment in the same procedure. Even if a previous EGD shows no abnormalities and serious concerns regarding the clinical situation remain, another EGD should be performed rather than choosing CE. If the patient's comfort is the issue, new ultra-thin nasogastric endoscopic instruments may offer an alternative. However, their potential needs to be evaluated.

Looking at the potential of $\mathrm{CE}$ in the stomach, things become even worse. One of the first maneuvers every trainee in gastroenterology learns is to inflate the stomach with air thereby improving the view. How can we expect that the findings in CE are similar or even superior to conventional EGD in a fasted patient swallowing the capsule? This technical problem may explain why when looking up the term 'capsule endoscopy' in PubMed in the 500 studies published from 2004 to 2005 , not one points out that CE helps to detect lesions in the stomach. Still, Peter et al. make another point in this connection. They just tell us that it is worthwhile to 'reintroduce the cord' if CE hints a missed finding after EGD. This suggestion seems adequate and does not really imply a brighter future for CE in the diagnostic work-up of the upper GI tract. For the small intestine, the double-balloon technique has the potential of becoming the standard of enteroscopy very likely replacing the conventional push enteroscopy and intraoperative enteroscopy. It already appears to be superior to $\mathrm{CE}$ in the diagnosis of small-intestinal polyps, whereas the value for diagnosing GI bleeding of obscure origin is similar $[8,9]$. 


\section{References}

1 Mylonaki M, Fritscher-Ravens A, Swain P: Wireless capsule endoscopy: a comparison with push enteroscopy in patients with gastroscopy and colonoscopy negative gastrointestinal bleeding. Gut 2003;52:1122-1126.

2 Neu B, Ell C, May A, Schmid E, Riemann JF, Hagenmuller F, Keuchel M, Soehendra N, Seitz U, Meining A, Rosch T: Capsule endoscopy versus standard tests in influencing management of obscure digestive bleeding: results from a German multicenter trial. Am J Gastroenterol 2005;100:1736-1742.

3 Pennazio M, Santucci R, Rondonotti E, Abbiati C, Beccari G, Rossini FP, De Franchis R: Outcome of patients with obscure gastrointestinal bleeding after capsule endoscopy: report of 100 consecutive cases. Gastroenterology 2004; 126:643-653.
4 Eliakim R, Sharma VK, Yassin K, Adler SN, Jacob H, Cave DR, Sachdev R, Mitty RD, Hartmann D, Schilling D, Riemann JF, BarMeir S, Bardan E, Fennerty B, Eisen G, Faigel D, Lewis BS, Fleischer DE: A prospective study of the diagnostic accuracy of PillCam ESO esophageal capsule endoscopy versus conventional upper endoscopy in patients with chronic gastroesophageal reflux diseases. J Clin Gastroenterol 2005:39:572-578.
5 Eliakim R, Yassin K, Shlomi I, Suissa A, Eisen GM: A novel diagnostic tool for detecting oesophageal pathology: the PillCam oesophageal video capsule. Aliment Pharmacol Ther 2004; 20:1083-1089.

6 Neu B, Wettschureck E, Rosch T: Is esophageal capsule endoscopy feasible? Results of a pilot. Endoscopy 2003;35:957-961.

7 Németh A, Rácz I: Capsule endoscopy of the esophagus (abstract)? Z Gastroenterol 2004; 42:429.

8 Matsumoto T, Esaki M, Moriyama T, Nakamura S, Iida M: Comparison of capsule endoscopy and enteroscopy with the double-balloon method in patients with obscure bleeding and polyposis. Endoscopy 2005;37:827-832.

9 Yamamoto H, Kita H: Double-balloon endoscopy. Curr Opin Gastroenterol 2005;21:573577. 